\title{
Influência da gestação e do puerpério no lipidograma de bovinos da raça Holandesa
}

\author{
[Influence of gestation and puerperium on the lipid profile of Holstein cattle] \\ F.C. Pogliani, M.R. Azedo, R.M. Souza, R.F.S. Raimondo, E.H. Birgel Junior ${ }^{*}$ \\ Faculdade de Medicina Veterinária e Zootecnia - USP - São Paulo, SP \\ Av. Prof. Dr. Orlando Marques de Paiva, 87 \\ 05508-900 - São Paulo, SP \\ RESUMO
}

\begin{abstract}
Avaliou-se a influência da gestação e do puerpério no lipidograma de bovinos da raça Holandesa por meio da determinação de colesterol, triglicérides, ácidos graxos não esterificados (AGNE), $\beta$ hidroxibutirato $(\beta-\mathrm{HBO})$ e glicose em 80 amostras de soro e plasma sangüíneo. Os animais foram distribuídos em cinco grupos (G) experimentais: G1 - constituído por 16 fêmeas não prenhes; G2 -18 fêmeas na fase inicial da gestação (com até três meses); G3 - 15 fêmeas prenhes, entre três e seis meses de gestação; G4 - 15 fêmeas na fase final da gestação (entre seis e nove meses); G5 - 16 fêmeas recémparidas, com até 30 dias de puerpério. Houve influência da gestação sobre o lipidograma, pois os teores séricos de AGNE foram mais altos no terço final da gestação, enquanto os teores séricos de $\beta-\mathrm{HBO}$ foram mais elevados durante o terço inicial de gestação. O puerpério influenciou os constituintes do lipidograma, pois, nos primeiros 30 dias após a parição, os teores séricos de AGNE e $\beta$ - HBO foram mais altos, enquanto os de triglicérides foram mais baixos nos animais no puerpério em relação aos que estavam em gestação.
\end{abstract}

Palavras-chave: bovino, lipidograma, gestação, raça Holandesa

\begin{abstract}
In order to establish the influence of gestation and puerperium on the lipid profile of Holstein cattle, the concentrations of cholesterol, triglycerides, nonesterified fatty acids (NEFA), $\beta$-hydroxibutyrate $(\beta-H B O)$, and glucose were determined in samples of serum and plasma from 80 animals distributed into five experimental groups $(G): G 1$ - 16 non pregnant females; $G 2-18$ females in the initial phase of gestation, up to three months; G3 -15 pregnant females, with gestation from three to six months; G4 - 15 females in the last stage of gestation, from six to nine months; G5 - 16 females soon after delivering, up to 30 days in puerperium. The lipid profile of healthy Holstein cows was influenced by gestation. The concentration of NEFA was higher in the last trimester of gestation while the serum concentration of $\beta$ $H B O$ was higher in the first trimester of gestation. In the first 30 days after delivering, the concentrations of NEFA and $\beta-H B O$ were higher, while those of triglycerides were lower when compared to those of cows during gestation.
\end{abstract}

Keywords: bovine, lipid profile, gestation, Holstein

\section{INTRODUÇÃO}

As vacas produtoras de leite, principalmente as de elevada produção, apresentam, durante a fase final da gestação e início da lactação, importantes mudanças metabólicas decorrentes das necessidades nutricionais para o desenvolvimento fetal no final da gestação e do aumento na demanda de nutrientes pela glândula mamária associado à lactogênese (Pogliani, 2006). No período do periparto, observa-se grande incidência de doenças como a esteatose

Recebido em 7 de maio de 2009

Aceito em 6 de abril de 2010

*Autor para correspondência (corresponding author)

E-mail: ehbirgel@usp.br 
hepática e a cetose, e a importância dos distúrbios metabólicos nessa fase tem motivado diversos pesquisadores a estudar o perfil metabólico dos bovinos (Pogliani, 2006).

$\mathrm{Na}$ literatura brasileira, existem somente duas pesquisas sobre a influência da gestação e do puerpério no lipidograma de bovinos (Costa, 1991; Souza, 2005). Costa (1991) constatou que os teores de colesterol diminuíram com o evoluir da gestação e aumentaram gradualmente durante o primeiro mês após o parto, enquanto os teores séricos de triglicérides apresentaram comportamento inverso, ou seja, aumentaram à medida que a gestação evoluiu e, após a parição, esses teores diminuíram gradativamente nos primeiros 30 dias após o parto. Com relação aos ácidos graxos não esterificados (AGNE), Costa (1991) verificou que a gestação não influenciou esses valores; porém, nos primeiros 30 dias pósparto, ocorreu aumento nos valores séricos desse constituinte do lipidograma. Tal aumento nos valores de AGNE é decorrente da maior mobilização das reservas corpóreas de gordura no período próximo ao parto e, principalmente, do estabelecimento da lactação, caracterizando um desequilíbrio entre a quantidade de alimento ingerido e as necessidades alimentares das vacas. Os teores séricos de triglicérides foram menores durante a fase de maior produção de leite, devido, provavelmente, à maior demanda pela glândula mamária (Costa, 1991).

Souza (2005) demonstrou a influência do puerpério e da fase pós-puerperal nos valores do lipidograma de fêmeas bovinas sadias da raça
Holandesa, sendo que, com a evolução do puerpério, gradativamente os teores séricos de colesterol aumentaram, enquanto os teores de ácidos graxos não esterificados diminuíram. $\mathrm{Na}$ fase pós-puerperal, ocorreu a estabilização dos valores de colesterol e de ácidos graxos não esterificados (AGNE). Souza (2005) verificou, ainda, que o puerpério e a fase pós-puerperal não influenciaram os teores séricos de betahidroxibutirato $(\beta-\mathrm{HBO})$ e plasmáticos da glicose.

A existência de poucas informações na literatura brasileira relativa ao metabolismo lipídico e, principalmente, a ausência, no Brasil, de pesquisas adequadamente planejadas para avaliar a influência de fatores indutores da variação dos seus valores em bovinos estimularam a elaboração da presente pesquisa, cujo objetivo foi o de estudar a influência da gestação e do puerpério no lipidograma de bovinos da raça Holandesa.

\section{MATERIAL E MÉTODOS}

Foram colhidas amostras de soro e plasma sangüíneo de bovinos da raça Holandesa, criados em nove propriedades produtoras de leite dos tipos A e B, localizadas no estado de São Paulo. Os animais utilizados foram distribuídos, segundo a fase da gestação e o puerpério, em cinco grupos (Tab. 1). Procurando-se evitar possível influência da lactação sobre o lipidograma, foram incluídos apenas novilhas e animais de primeira gestação, com faixa etária variando entre 15 e 36 meses.

Tabela 1. Constituição dos grupos experimentais para avaliação da influência da gestação e puerpério no lipidograma de fêmeas bovinas sadias da raça Holandesa

\begin{tabular}{cl} 
Grupos & \multicolumn{1}{c}{ Constituição } \\
\hline G1 & 16 fêmeas sadias não prenhes \\
G2 & 18 fêmeas sadias na fase inicial da gestação, com até três meses de gestação \\
G3 & 15 fêmeas sadias prenhes, período de gestação: entre três e seis meses \\
G4 & 15 fêmeas sadias na fase final da gestação: entre seis e nove meses \\
G5 & 16 fêmeas sadias recém-paridas, com até 30 dias de puerpério \\
\hline
\end{tabular}

As amostras de sangue foram colhidas por meio da punção da veia jugular, utilizando-se o Sistema Vacutainer. As amostras para avaliação do colesterol, triglicérides, AGNE e B-HBO foram colhidas em tubos de vidro siliconizados sem anticoagulantes e mantidas em temperatura ambiente para facilitar a retração do coágulo. As amostras para avaliação de glicose foram colhidas em tubos de vidro siliconizados contendo fluoreto de sódio e mantidas refrigeradas durante o transporte. Em seguida, as amostras foram centrifugadas a $1000 \mathrm{~g}$, durante 15 minutos, para a ocorrência da sinérese do coágulo ou sedimentação dos elementos 
figurados do sangue, sendo o soro e o plasma sangüíneos separados por aspiração e conservados a menos $20^{\circ} \mathrm{C}$ até a realização das provas.

Os constituintes do lipidograma foram quantificados por metodologia enzimática colorimétrica (Analisador Bioquímico modelo Liasys - AMS - Itália), utilizando-se kit comercial. A determinação dos teores séricos de AGNE (Kit FA 115 - Randox $^{\circledR}$ - Irlanda), colesterol (Kit $\mathrm{N}^{\mathrm{O}} 11505$ - Biosystems ${ }^{\circledR}$ Espanha), triglicérides (Kit $\mathrm{N}^{\mathrm{o}} 11528$ Biosystems ${ }^{\circledR}$ - Espanha) e B-HBO (Kit FA 1007 Randox $^{\circledR}$ - Irlanda) foi realizada, respectivamente, de acordo com as recomendações de Elphick (1968), Allain et al. (1974), Fossati e Prencipe (1982) e Williamson et al. (1962), enquanto a determinação dos teores plasmáticos de glicose (Kit $\mathrm{N}^{0} 10.250 .021$ Diasys ${ }^{\circledR}$ - Alemanha) foi realizada utilizando-se o método descrito por Barham e Trinder (1972).

Os testes estatísticos, comparando as médias obtidas nos vários grupos experimentais e a determinação da média aritmética, o desviopadrão e a amplitude de variação dos resultados obtidos, foram calculados por meio dos programas Microsoft Excel XP ${ }^{\circledR}$, SPSS 11.0 for Windows ${ }^{\circledR}$, Minitab 14.0 for Windows ${ }^{\circledR}$.

Para a análise estatística, utilizou-se metodologia em que as médias foram comparadas duas a duas segundo o método de Bonferroni, ou agrupadas segundo o método descrito de Calinski e Corsten (Calinski e Corsten, 1985; Neter et al., 1996), sendo utilizados os métodos de Calinski e Corsten para as variáveis AGNE, $\beta$-HBO e glicose, e de Bonferroni para as variáveis triglicérides e colesterol.

\section{RESULTADOS}

A análise dos resultados apresentados na Fig. 1 mostra que os teores séricos de colesterol não foram influenciados pela fase da gestação ou do puerpério, sendo que, nos diversos grupos experimentais os seus valores médios oscilaram entre $92,42 \pm 19,73 \mathrm{mg} / \mathrm{dl}$ e $129,97 \pm 63,12 \mathrm{mg} / \mathrm{dl}$.
Verificou-se que o puerpério influencia os teores séricos de triglicérides (Fig. 2), pois os valores encontrados para essa variável no grupo de fêmeas recém-paridas, com até 30 dias de puerpério, foram significativamente menores $(12,35 \pm 5,70 \mathrm{mg} / \mathrm{dl})$ daqueles observados em vacas não prenhes $(29,60 \pm 16,32 \mathrm{mg} / \mathrm{dl})$ e em gestação (entre 29,44 $\pm 9,55 \mathrm{mg} / \mathrm{dl} \quad \mathrm{e}$ $38,46 \pm 21,64 \mathrm{mg} / \mathrm{dl})$. Constatou-se que não havia diferenças estatísticas significantes entre o grupo de fêmeas não prenhes e de fêmeas prenhes (com até três meses, entre três e seis meses e entre seis e nove meses de gestação), evidenciando que a gestação não foi um fator de influência para essa variável.

A análise dos resultados mostra a influência da gestação e do puerpério nos teores séricos AGNE (Fig. 3), pois os valores encontrados para essa variável no grupo de fêmeas com seis a nove meses de gestação $(271,25 \pm 144,99 \mu \mathrm{M} / \mathrm{L})$ e no grupo de fêmeas recém-paridas, com até 30 dias de puerpério $(394,18 \pm 236,83 \mu \mathrm{M} / \mathrm{L})$, foram significativamente maiores do que aqueles observados em vacas não prenhes $(190,13 \pm 130,87 \mu \mathrm{M} / \mathrm{L})$, fêmeas com até três meses de gestação $(196,56 \pm 131,88 \mu \mathrm{M} / \mathrm{L})$ e fêmeas com três a seis meses de gestação $(220,39 \pm 83,46 \mu \mathrm{M} / \mathrm{L})$.

Com relação aos teores séricos de $\beta$-HBO (Fig. 4), observou-se que, no grupo de fêmeas com até três meses de gestação $(4,55 \pm 1,83 \mathrm{mg} / \mathrm{dl})$ e de fêmeas recém-paridas com até 30 dias de puerpério $(4,75 \pm 2,12 \mathrm{mg} / \mathrm{dl})$, os valores médios da concentração sérica de $\beta-\mathrm{HBO}$ eram estatisticamente maiores do que os encontrados para os grupos de fêmeas vazias $(2,99 \pm 0,85 \mathrm{mg} / \mathrm{dl})$, fêmeas com três a seis meses de gestação $(3,49 \pm 0,95 \mathrm{mg} / \mathrm{dl})$ e fêmeas com seis a nove meses de gestação $(3,35 \pm 1,04 \mathrm{mg} / \mathrm{dl})$.

Os teores plasmáticos de glicose (Fig. 5) nos animais não prenhes $(72,25 \pm 8,63 \mathrm{mg} / \mathrm{dl})$ foram significativamente maiores do que os observados em vacas prenhes (entre 63,26 $\pm 5,92$ e $66,38 \pm 4,59 \mathrm{mg} / \mathrm{dl}$ ) e em vacas recém-paridas, com menos de 30 dias de evolução do puerpério $(66,73 \pm 5,95 \mathrm{mg} / \mathrm{dl})$. 


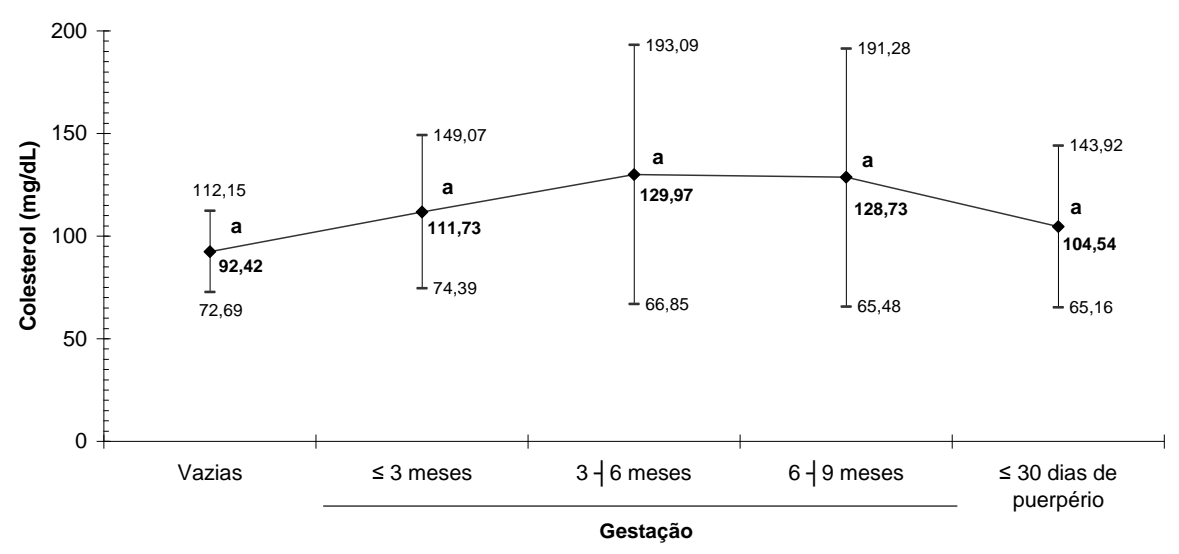

Letras diferentes indicam diferença estatística significante, método de Bonferroni $(\mathrm{P} \leq 0,05)$.

Figura 1. Média e desvio-padrão dos teores séricos de colesterol, segundo a fase de gestação e do puerpério de bovinos da raça Holandesa.

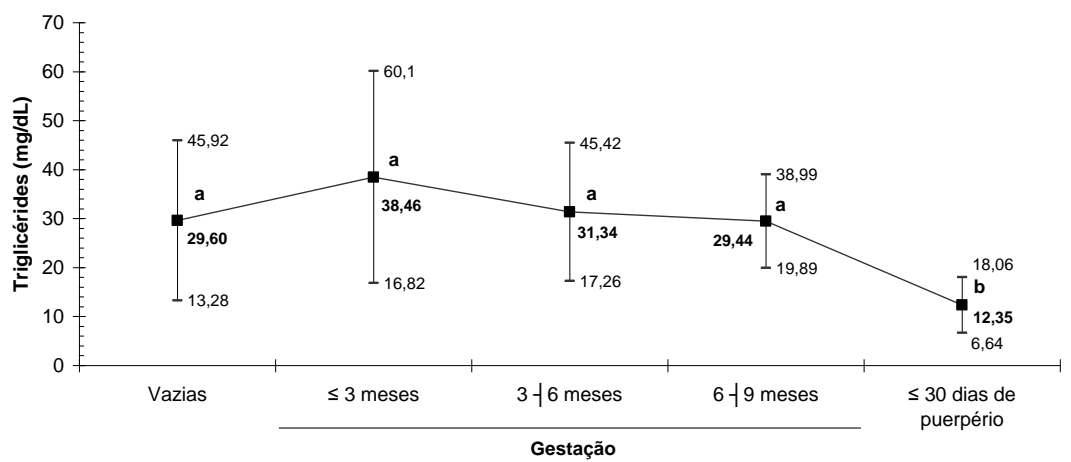

Letras diferentes indicam diferença estatística significante, método de Bonferroni $(\mathrm{P} \leq 0,05)$

Figura 2. Média e desvio-padrão dos teores séricos de triglicérides, segundo a fase de gestação e do puerpério de bovinos da raça Holandesa.

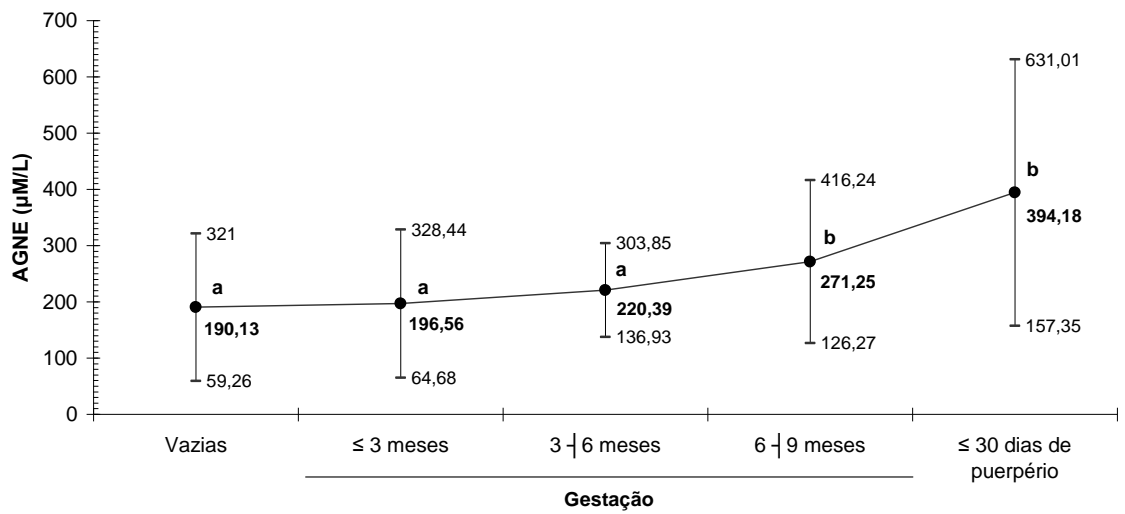

Letras diferentes indicam diferença estatística significante, método de Calinski e Corsten $(\mathrm{P} \leq 0,05)$.

Figura 3. Média e desvio-padrão dos teores séricos de ácidos graxos não esterificados (AGNE), segundo a fase de gestação e do puerpério de bovinos da raça Holandesa. 


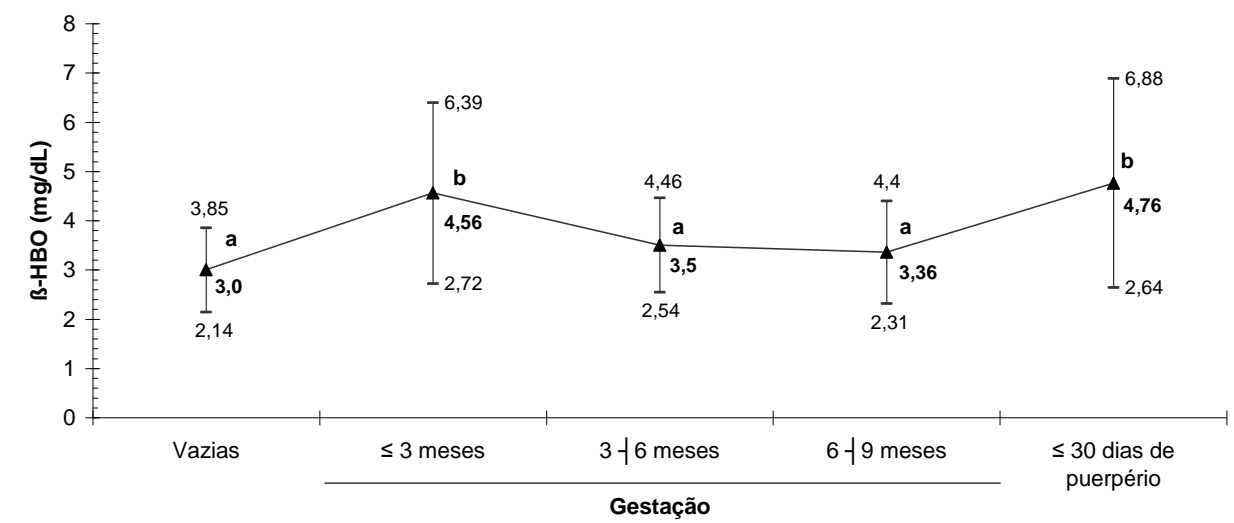

Letras diferentes indicam diferença estatística significante, método de Calinski e Corsten $(\mathrm{P} \leq 0,05)$.

Figura 4. Média e desvio-padrão dos teores séricos de beta-hidroxibutirato ( $\beta$-HBO), segundo a fase de gestação e do puerpério de bovinos da raça Holandesa.

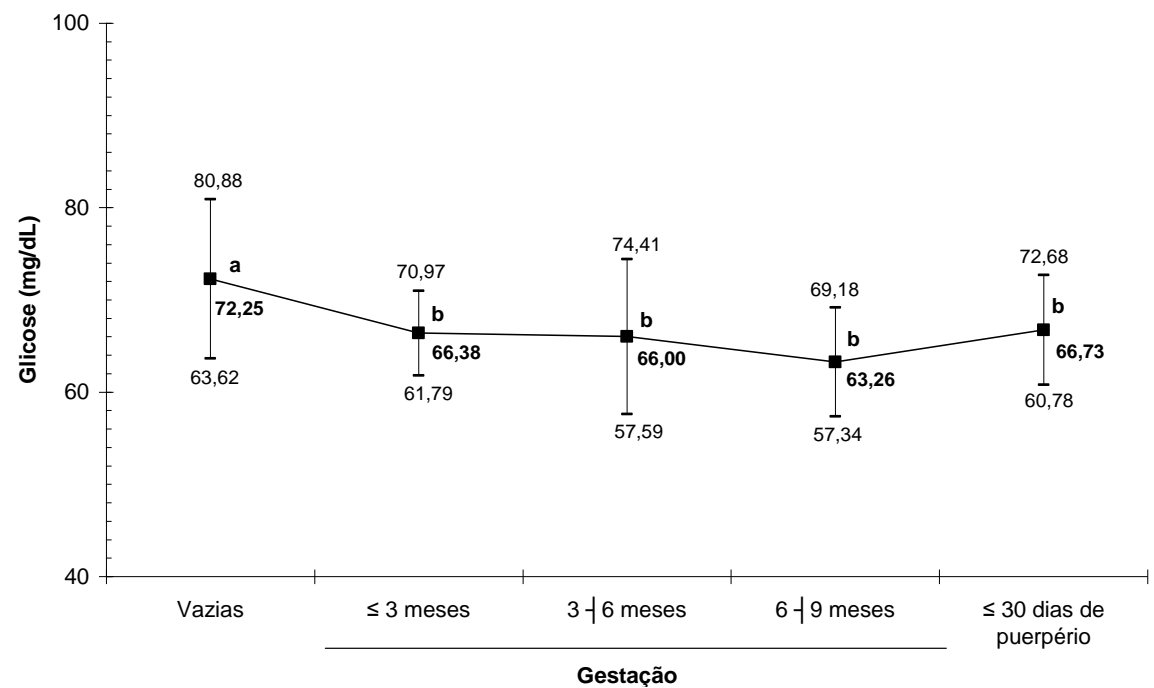

Letras diferentes indicam diferença estatística significante, método de Calinski e Corsten $(\mathrm{P} \leq 0,05)$

Figura 5. Média e desvio-padrão dos teores plasmáticos de glicose, segundo a fase de gestação e do puerpério de bovinos da raça Holandesa.

\section{DISCUSSÃO}

Constatou-se a existência de uma absoluta concordância entre os autores de que no puerpério os teores séricos de ácidos graxos não esterificados (AGNE) são mais elevados do que os observados nos dois primeiros terços da gestação ou na fase pós-puerperal (Christie, 1981; Costa, 1991; Bronicki e Dembinski, 1995; Santos, 1998; Rennó Neto, 2004; Souza, 2005), sendo que esse aumento já pode ser observado no terço final da gestação. O aumento de AGNE no periparto é consequiência de dois fatores: a queda da ingestão de alimento e o aumento de hormônios lipolíticos (Vazquez-Añon et al., 1994). Segundo Herdt (1988), próximo ao parto, as concentrações séricas de lactogênio placentário e prolactina aumentam, sendo que após a parição, há aumento na concentração do hormônio de crescimento (GH). Essas mudanças, associadas à diminuição dos níveis séricos de insulina e glicose, promovem aumento da liberação de ácidos graxos a partir do tecido adiposo, determinando o aumento dos teores séricos de AGNE durante o periparto. 
O estabelecimento de balanço energético negativo associado à alta concentração de AGNE no sangue (o qual seria substrato para a cetogênese) determina o aumento dos níveis séricos de $\beta$-HBO durante o puerpério, essas observações estão em concordância com aquelas referidas na literatura (Schwalm e Schultz, 1976; Pösö et al., 1994; Santos, 1998).

Relativo aos teores séricos de $\beta$-HBO observados durante a gestação, encontrou-se maior valor dos resultados no terço inicial da gestação, sendo que, a princípio, essa alteração não poderia ser explicada em virtude da maior demanda energética, pois nesse período os fetos estavam em fase inicial e não havia distúrbios relacionados à lactação, já que todos os animais utilizados eram novilhas. A análise dos resultados evidencia que, nesse período, não existiam indícios da ocorrência de hipoglicemia no período ou outros distúrbios relacionados aos lípides, pois os valores de AGNE e triglicérides não variaram no período, ou seja, o AGNE não foi substrato para a cetogênese. Concluiu-se que esses resultados podem refletir a melhora nas condições alimentares, num primeiro momento, tais modificações determinam maior formação e absorção de corpos cetônicos durante a fermentação ruminal, ou seja, os resultados encontrados para $\beta$-HBO seriam reflexo de cetogênese alimentar (Pogliani, 2006).

Em relação às diferenças dos valores de glicose entre as novilhas não prenhes e em gestação, observou-se que, no grupo de fêmeas vazias, obteve-se o maior teor plasmático de glicose, sendo que esse período ocorre simultaneamente ao período de menor nível sérico de $\beta$-HBO encontrado.

Ao compararem-se os resultados de glicose observados nessa pesquisa para novilhas vazias, observou-se que os teores plasmáticos eram semelhantes aos observados em animais jovens referidos por Pogliani (2006). Provavelmente as variações observadas nos teores plasmáticos de glicose das novilhas vazias foram decorrentes da influência de fatores etários. A influência do puerpério e/ou produção de leite nos teores plasmáticos de glicose em decorrência da alta demanda de glicose para a síntese de lactose (Schwalm e Schultz, 1976; Blum et al., 1983; Kappel et al., 1984; Vazquez-Añon et al., 1994) não foi observada nos resultados da presente pesquisa.

Quanto aos valores de triglicérides, pode-se observar que a concentração sérica média desse lipídio foi estatisticamente menor para as fêmeas recém-paridas do que os valores obtidos durante o período gestacional. Essa observação está de acordo com a relatada na literatura consultada (Varman e Schultz, 1968; Pehrson, 1971; Emery et al., 1992). A diminuição da concentração de triglicérides no sangue no período pós-parto seria explicada pela baixa capacidade hepática em sintetizar e/ou secretar VLDL (lipoproteína de densidade muito baixa), determinando, em virtude da entrada lenta e crônica de triglicérides no fígado, o aparecimento de esteatose hepática, que poderia comprometer, inclusive, a sua função (Gruffat et al., 1996; Van Den Top et al., 2005).

Ao analisar a literatura sobre a influência da gestação nos teores séricos de colesterol, verificou-se que, nas diversas pesquisas realizadas, foram utilizadas vacas pluríparas e em lactação, sendo a intenção avaliar a possível influência da lactação (Varman; Schultz, 1968; Perhson, 1971; Schwalm e Schultz, 1976; Blum et al., 1983; Kappel et al., 1984; Kweon et al., 1986; Van Den Top et al., 2005). Assim, as discrepâncias entre os resultados obtidos nessa pesquisa com aqueles referidos na literatura podem ser justificadas, pois foi demonstrado que, em animais que não estão em lactação, a gestação não influencia os teores séricos de colesterol.

Segundo a revisão de literatura, durante o periparto, ocorre a diminuição dos teores séricos de colesterol em decorrência da esteatose hepática observada nesse período (Souza, 2005). No momento do parto, são observados os menores teores séricos de colesterol, sendo que, durante o puerpério, os teores séricos de colesterol aumentam (Kappel et al., 1984; Costa, 1991; Bronicki e Dembinski, 1995; Gueorguieva e Gueorguiev, 1997; Souza, 2005) e, entre 45 e 90 dias após o parto, os valores tendem à estabilização (Kappel et al., 1984; Souza, 2005).

Em virtude da influência de fatores etários nesse período (Pogliani, 2006), a decisão de utilizar apenas novilhas e animais de primeira gestação contribuiu para a diminuição dos valores médios 
de colesterol obtidos durante a prenhez e pode ser o motivo de os resultados da presente pesquisa não terem evidenciado a influência do puerpério nos teores séricos de colesterol. Por outro lado, os resultados obtidos na presente pesquisa são sugestivos de que, em vacas primíparas, os distúrbios do metabolismo lipídico são menos intensos, e o aumento dos teores de colesterol no puerpério, com retorno aos patamares observados antes do parto, ocorreria precocemente, nos primeiros 30 dias após o parto.

\section{CONCLUSÕES}

A gestação influenciou o lipidograma, pois os teores séricos de AGNE foram maiores no terço final da gestação, enquanto os teores séricos de $\beta$ - HBO foram maiores durante o terço inicial de gestação. Observou-se a significativa influência do puerpério nos constituintes do lipidograma, pois, nos primeiros 30 dias após a parição, os teores séricos de AGNE e $\beta-\mathrm{HBO}$ foram maiores, enquanto os de triglicérides foram menores nos animais no puerpério em relação aos que estavam em gestação.

\section{REFERÊNCIAS BIBLIOGRÁFICAS}

ALLAIN, C.C.; POON, L.S.; CHAN, C.S.G. et al. Enzymatic determination of total serum cholesterol. Clin. Chem., v.20, p.470-475, 1974.

BARHAM, D.; TRINDER, P. An Improved colour reagent for the determination of blood glucose by the oxidase system. Analyst, v.97, p.142-145, 1972.

BLUM, J.W.; KUNZ, P.; LEUENBERGER, H. Thyroid hormones, blood plasma metabolites and haematological parameters in relationship to milk yield in dairy cows. Anim. Prod., v.36, p.93-104, 1983.

BRONICKI, M.; DEMBINSKI, Z. Evaluation of the post-natal fertility in dairy cows with lipid metabolism disturbances at various intensities. Bull. Vet. Inst. Pulawy, v.39, p.39-42, 1995.

CALINSKI, T.; CORSTEN, L.C.A. Clustering means in ANOVA by simultaneous testing. Biometrics, v.41, p.39-48, 1985.
CHRISTIE, W. W. Effects of diet on lipid composition In: CHRISTIE, W.W. (Ed). Lipid metabolism in ruminants animals. Oxford: Pergamon, 1981. 452p.

COSTA, S.G. Perfil lipídico de vacas Holandesas, variedade HPB, em diferentes fases da gestação, 1991. 57f. Dissertação (Mestrado) Faculdade de Medicina Veterinária e Zootecnia, Universidade de São Paulo, São Paulo.

ELPHICK, M.C. Modified colorimetric ultramicro method for estimating NEFA in serum. J. Clin. Pathol., v.21, p.567-570, 1968.

EMERY, R.S.; LIESMAN, J.S.; HERDT, T. Metabolism of long chain fatty acids by ruminant liver. J. Nutr., v.122, p.832-837, 1992.

FOSSATI, P.; PRENCIPE, L. Serum triglycerides determined colorimetrically with an enzyme that produces hydrogen peroxide. Clin. Chem., v.28, p.2077-2080, 1982

GRUFFAT, D.; DURAND, D.; GRAULET, B. et al. Regulation of VLDL synthesis and secretion in the liver. Reprod. Nutr. Devel., v.36, p.375-389, 1996.

GUEORGUIEVA, T.M.; GUEORGUIEV, I.P. Serum cholesterol concentration around

parturition and in early lactation in dairy cows. Rev. Med. Vet., v.148, p.241-244, 1997.

HERDT, T.H. Fuel homeostasis in the ruminant, Vet. Clin. N. Am.: Food Anim. Pract., v.4, p.213231, 1988.

KAPPEL, L.C.; INGRAHAM, R.H.; MORGAN, E.B. et al. Relationship between fertility and blood glucose and cholesterol concentration in Holstein cows. Am. J. Vet. Res., v.45, p.26072612, 1984.

KWEON, O.K.; ONO, H.; OSACA, K. et al. Factors affecting serum total cholesterol level of lactating Holstein cows. Jpn. J. Vet. Sci., v.48, p.481-486, 1986.

NETER, J.; KUTNER, M.H.; NACHTSHEIN, C.J. et al. (Eds). Applied linear models. Chicago: Irwin, 1996. 1408p.

PEHRSON, B. Studies of the blood lipid pattern in healthy dairy cows. Acta Vet. Scand., v.12, p.230-242, 1971. 
POGLIANI, F.C. Valores de referência $e$ influência dos fatores etários, sexuais e da gestação no lipidograma de bovinos da raça Holandesa, criados no Estado de São Paulo. 2006. 134f. Dissertação (Mestrado) - Faculdade de Medicina Veterinária e Zootecnia, Universidade de São Paulo, São Paulo.

PÖSÖ, A.R.; LINDBERG, L.A. Plasma protein synthesis and serum amino acids in dry and lactating dairy cows. J. Vet. Med., v.41, p.72-75, 1994.

RENNÓ NETO, B.P. Influência da aplicação da somatotropina recombinante bovina na função hepática, renal e lipidograma de bovinos da raça Holandesa em lactação. 2004. 116f. Dissertação (Mestrado) - Faculdade de Medicina Veterinária e Zootecnia, Universidade de São Paulo, São Paulo.

SANTOS, M.V. Correlação entre ácido ascórbico plasmático, contagem de células somáticas no leite e o perfil metabólico de vacas secas e em lactação. 1998. 97f. Dissertação (Mestrado) - Faculdade de Medicina Veterinária e Zootecnia, Universidade de São Paulo, São Paulo.

SCHWALM, J.W.; SCHULTZ, L.H. Relationship of insulin concentration to blood metabolites in the dairy cow. J. Dairy Sci., v.59, p.255-261, 1976.
SOUZA, R.M. Avaliação da função hepática e do lipidograma no período puerperal e póspuerperal e suas inter-relações com os distúrbios reprodutivos de fêmeas bovinas da raça Holandesa, criadas no Estado de São Paulo. 2005. 192f. Dissertação (Mestrado) - Faculdade de Medicina Veterinária e Zootecnia, Universidade de São Paulo, São Paulo.

VAN DEN TOP, A.; VAN TOL, A.; JANSEN, $H$. et al. Fatty liver in dairy cows post partum is associated with decreased concentration of plasma triacylglycerols and decreased activity of lipoprotein lipase in adipocytes. J. Dairy Res., v.72, p.129-137, 2005.

VARMAN, P.N.; SCHULTZ, L.H. Blood lipids of cows at different stages of lactation. J. Dairy Sci., v.51, p.1971-1974, 1968.

VAZQUEZ-AÑON, M.; BERTICS, S.; LUCK, M. et al. Peripartum liver triglyceride and plasma metabolites in dairy cows. J.Dairy Sci., v.77, p.1521-1528, 1994

WILLIAMSON, D.H.; MELLANBY, J.; KREBS, H.A. Enzymatic determination of D(-) ß-hydroxybutyric acid and acetoacetic acid in blood. Biochem. J., v.82, p.90, 1962. 